\title{
PERFORMANCE OF STEEL SLAG AS FINE AGGREGATE IN STRUCTURAL CONCRETE
}

\author{
K. A. Olonade ${ }^{1, *}$, M. B. Kadiri' ${ }^{2}$ and P. O. Aderemi ${ }^{3}$ \\ 1, 2, 3 DePARTMENT OF CiVIL ENGineERING, OBAFEMI Awolowo UNIVERSITY, IFE, OSUN STATE. NIGERIA \\ Email addresses:1 olonade1431ah@gmail.com, 2 mikebabs28@yahoo.com,3 hmesteem@yahoo.com
}

\begin{abstract}
Suitability of using steel slag (SS) as substitute for sand in concrete was investigated. SS was collected from a dump site, crushed manually and sieved through between sieves No. 4 and 200. SS was characterized using XRF and XRD techniques. Concrete of mix ratio 1:2:4 was batched by weight with slag replacement levels of 0 to 100\% of sand at 25\% interval and the concrete specimens (cubes and beams) produced were cured in water for 7, 14, 28 and 56 days. Water demand, compressive strength as well as flexural strength of the concrete were determined. Results indicated that SS contained high amorphous silica (42.40\%) and ferric oxides (31.90\%) with traces of crystalline particles. The water-cement ratio reduced from 0.62 to 0.50 as slag proportion increased from $0 \%$ to $100 \%$ at slump range of $60 \pm 10 \mathrm{~mm}$. The strength of SS concrete increased with increase in proportion of SS. The study suggested that up to $50 \%$ of weight of sand could be replaced with slag to produce structural concrete.
\end{abstract}

Keywords: structural concrete, steel slag, fine aggregate, compressive strength and flexural strength

\section{INTRODUCTION}

Environmental sustainability has been subject of discourse virtually in all human endeavours, especially in construction industries, where natural raw materials are consumed tremendously. Concrete, the most consumed artificial materials, consists of fine and coarse aggregates that occupy $60 \%$ to $75 \%$ of the concrete volume ( $70 \%$ to $85 \%$ by mass) which strongly influence the concrete's freshly mixed and hardened properties, mixture proportions, and economy [1]. According to some estimates, after the year 2010, the global concrete industry required 8 to 12 billion metric tons of natural aggregates annually and over 2 billion tons of aggregates are consumed annually with about $40 \%$ of fine aggregates [2].

Conventional aggregates (fine or coarse) are mined from the earth, either dug out of pits or blasted out of quarries. This process has many significant environmental impacts [3].The need to mitigate these environmental stresses to make construction sustainable and to reduce rising costs of construction has necessitated research into the use of alternative cheap materials, more importantly, locally available ones which can replace conventional ones in concrete production. Non-conventional aggregates are usually sourced from agricultural and industrial wastes as well as concrete rubbles.

Kulkarni et al. [4] studied the use of textile mill sludge as fine aggregate in concrete production. They used different percentages of the sludge as replacement for sand which was combined with fly ash in concreting. Their results showed that concrete containing textile mill sludge (32\%) and fly ash (20\%) could be used to produce concrete whose strength is above $20 \mathrm{~N} / \mathrm{mm}^{2}$ and that increase in the sludge content reduces the workability. However, the durability of the concrete was not reported. Similar investigation was conducted by [5] in which fine aggregate (sand) was replaced with fly ash. The mechanical and physical properties of the concrete produced were studied. They found that concrete containing up to $15 \%$ fly ash has higher compressive and flexural strength than that of the normal concrete by 20 and $15 \%$ respectively. The results agreed with the findings of [6] and [7].

In the work of [8], copper slag (CS) was used as replacement for fine aggregate in concrete at replacement levels between 0 and $100 \%$ at an interval of $20 \%$. The strength behaviour of reinforced concrete slender column was investigated. It was observed that replacement of up to $40 \%$ of sand with CS caused no 
major changes in column failure load, stiffness or concrete strength. Other authors [9] and [10] found the use of CS as suitable partial replacement for fine aggregate. Quarry rock dust, marble sludge powder, crushed stone and conditioned pulverized ash as well as recycled concrete aggregates were common materials studied for use as replacement for artificial fine aggregates in concrete production [11], [12] and [13].

In Nigeria, steel is mainly produced from smelting of scrap metals and hundreds of tonnes of steel slag are produced every year. Approximately 96 to 145 million metric tons of steel slag are produced yearly [14]. Most often, steel slags are disposed around the steel producing centres posing environmental threats (Figure 1a). Different authors have reported the use of steel slag as aggregates in concrete with positive results [15], [16] and [17]. Not much research work has been reported on the use of steel slag produced from scrap metals, as produced in Nigeria. But recently Salau et al., [18] studied the use of steel slag as coarse aggregate in concrete. In their study, steel slag was used to replace granite between 0 and $100 \%$ at an interval of $20 \%$ for different mixes. Their results showed that up to $60 \%$ replacement of mix ratio 1:2:4 gave strength adequate for structural application, while 1:3:6 mix ratio gave lower strength compared to the control.

In this study, the suitability of using steel slag as fine aggregates in concrete was investigated. The physical and chemical properties of steel slag were also studied. The compressive and flexural strength of the steel slag aggregate concrete were equally examined. If found suitable, the volume of steel slag disposed indiscriminately will reduce, while sustainable construction would be ensured as scarce natural sand will be conserved. In addition, high cost of construction occasioned by high cost of conventional aggregates may be reduced.

\section{MATERIALS AND METHODS}

\subsection{Materials}

Steel slag (SS) was collected from the premises of Ife Steel and Iron Company, Ile-Ife, Osun State, Nigeria (Figure 1a). It was crushed and sieved so that the maximum and minimum particle sizes were $4.75 \mathrm{~mm}$ and $150 \mu \mathrm{m}$, respectively as shown in Figure $1 \mathrm{~b}$. This is to ensure that the crushed steel slag does not contain dust particles like normal river sand. The steel slag was used as fine aggregate to replace river sand at replacement levels of $0,25,50,75$ and $100 \%$. Coarse aggregate used was crushed granite of nominal maximum particle size of $19 \mathrm{~mm}$. The cement used in this study was Ordinary Portland Cement. Its chemical composition and that of the slag were determined using XRF technique, conducted at Centre for Energy Research and Development (CERD), Obafemi Awolowo University, Ile-Ife, Nigeria. The phase composition of the steel slag was also investigated using XRD method. Potable water was used for mixing.

\subsection{Mining Specimen Preparations and Testing Porgramme}

Concrete mixture was batched by weight in the ratio of 1:2:4 (cement: sand and steel slag: granite aggregate). In order to ensure the same consistency of the fresh concrete mixes for different amount of steel slag, mixing water was added until the slump value was in the range of $60 \pm 10 \mathrm{~mm}$ (true slump). Thereafter, water-cement ratio for each mix was determined. Five different mixes were prepared with varying contents of steel slag. Concrete cubes of size $150 \mathrm{~mm} \times 150 \mathrm{~mm} \times$ $150 \mathrm{~mm}$ were cast for compressive strength test while concrete beams of sizes $150 \times 150 \times 760 \mathrm{~mm}$ were produced for flexural strength testing. A total of sixty (60) concrete cubes and beams were prepared. The moulds were removed after 24 hours and cured in water for 7, 14, 28 and 56 days until testing day.

Particle size distribution of the aggregates (granite, sand and steel slag) used was carried out in compliance with the procedures described in ASTM C136. Also, their physical properties were determined. The slump test to determine workability of the fresh concrete mix was conducted as prescribed by BS 1881-103. Compressive strength of the concrete cube specimens was conducted at the end of each curing day in accordance with BS 1881 (Part 3). Prior to testing, the weight of the cube specimen was measured. For flexural testing, the experimental set-up is shown in Figure 2. Flexural strength for each of the beam specimens was determined using relationship recommended by ASTM C78. This is expressed in terms of Modulus of Rupture (MR). Average of three readings was recorded for each of the strength testing. The progression of flexural cracks as the load increases was equally monitored.

\section{RESULTS AND DISCUSSION}

\subsection{Chemical properties of cement and steel slag}

The chemical compositions of the cement, steel slag and sand as determined from XRF technique are presented in Table 1. It is observed that the cement composition is within the acceptable range specified by BS EN 196-2 (1995).

Vol. 34, No. 3, July 2015 


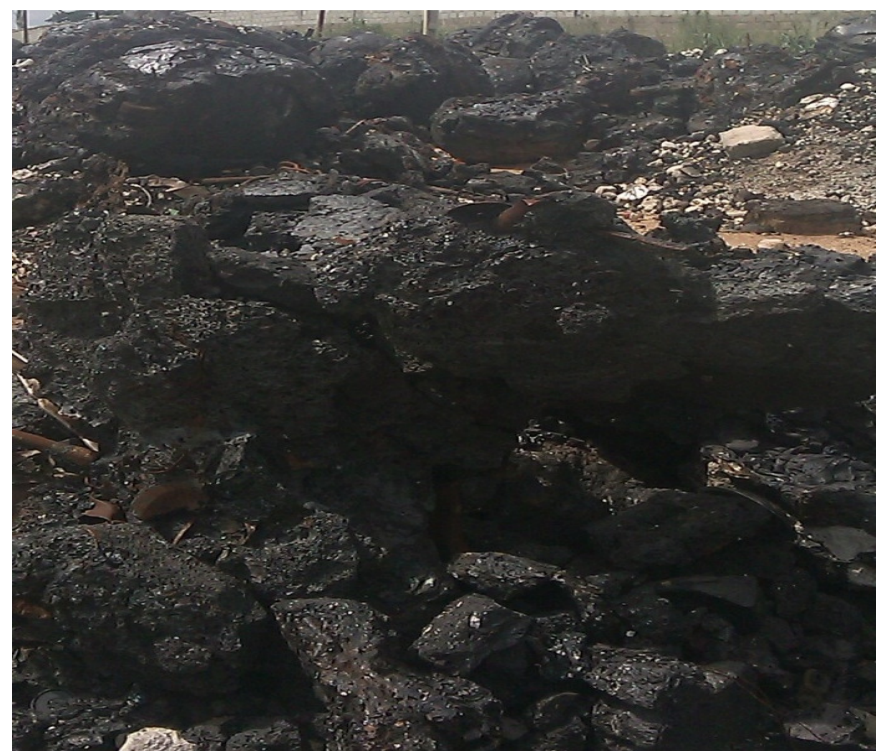

(a) Slag deposited at a factory in Nigeria

Figure 1: Raw and Crushed Slag

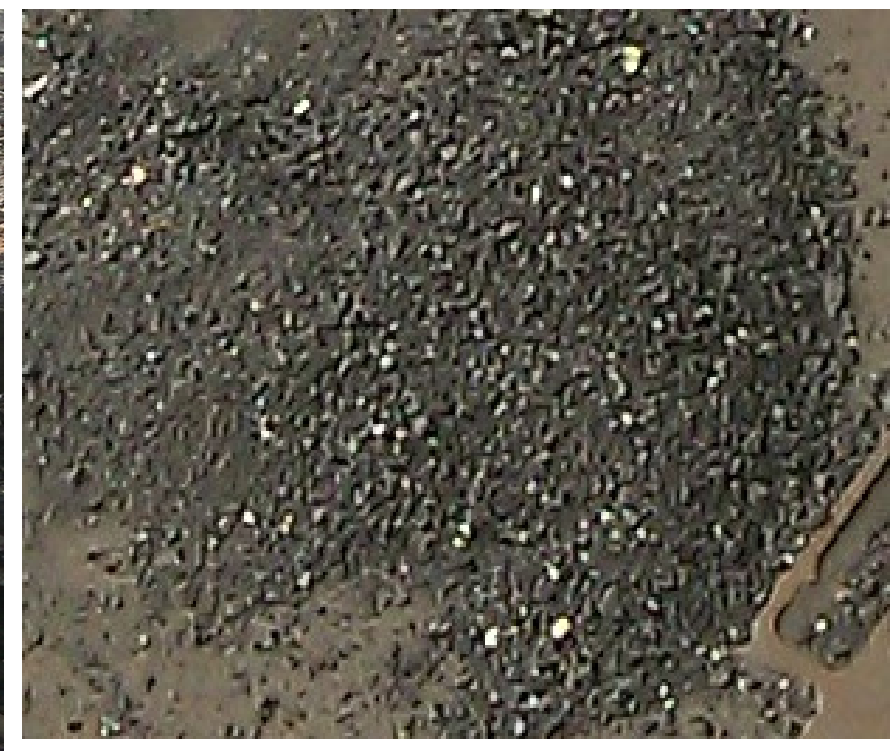

(b) Crushed slag into fine particles

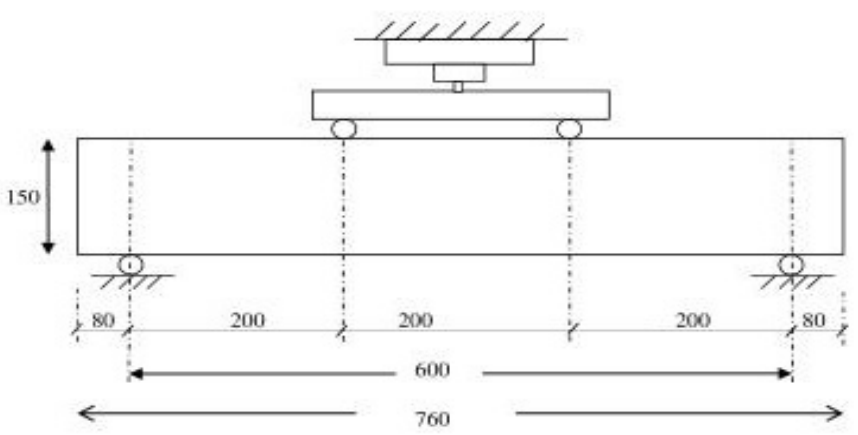

Figure 2: Experimental Set-up for Flexural Strength Testing

\subsection{Mixing, Specimen Preparations and Testing Programme}

Thus the cement can be categorized as Type I cement. The composition of steel slag showed that the three major oxides (silica, ferric and alumina) make up to $90 \%$ of the total content The silica content was $42.40 \%$, about $9 \%$ higher than what was specified by National Slag Association of USA [19], the alumina content was within the specified range of 7 to $16 \%$ but the iron oxide was $31.9 \%$ which was very high, compared to what was specified ( 0.1 to $1.5 \%$ ). The higher iron oxide content of the slag could be due to the composition of its source, scrap metal melting, processing and additives used. All other oxides were within the specified ranges.
On comparison with the sand to replace, sand consisted mainly silica $(90.80 \%)$ with traces of ferric $(1.30 \%)$ and alumina (4.15\%). The results suggested that the two materials (sand and steel slag) are different in composition indicating that differences observed in normal and SS concrete could be attributed to reduction in silica content and high alumina and ferric content in SS concrete.

The X-Ray diffraction (XRD) spectrum pattern of the slag, as shown in Figure 3, had one smeared peak with many short orders and bumps, where the major peaks were expected. Irregular base line with noise and pulsed shape are also observed. All these features suggested that the steel slag was mainly in amorphous phase with traces of crystalline structure. This behaviour may be attributed to the cooling method. According to [19], slag that is cooled rapidly after emerging from the furnace tends to form a glassy, noncrystalline material (amorphous) while slower cooling leads to crystallization of a number of minerals. The slag studied was collected from the heap of slag nearby factory (Figure 1), which showed that the slag might have been exposed to rapid and uncontrolled cooling of atmospheric air.

Table 1: Chemical Composition of Cement and Steel Slag

\begin{tabular}{cccccccccccc}
\hline \multirow{2}{*}{ Materials } & \multicolumn{10}{c}{ Major Oxides (\%) } \\
\cline { 2 - 10 } & $\mathrm{SiO}_{2}$ & $\mathrm{Al}_{2} \mathrm{O}_{3}$ & $\mathrm{Fe}_{2} \mathrm{O}_{3}$ & $\mathrm{CaO}$ & $\mathrm{MgO}$ & $\mathrm{Na}_{2} \mathrm{O}$ & $\mathrm{K}_{2} \mathrm{O}$ & $\mathrm{SO}_{3}$ & $\mathrm{Mn}_{2} \mathrm{O}_{3}$ & $\mathrm{LOI}^{2}$ \\
\hline Steel Slag & 42.40 & 15.00 & 31.90 & 5.00 & - & - & 2.05 & - & 0.2 & - \\
Sand & 90.80 & 4.150 & 1.30 & 0.00 & 0.00 & 0.00 & 0.32 & 0.00 & 0.09 & 1.87 \\
Cement & 18.33 & 5.00 & 2.75 & 60.11 & 1.15 & 0.23 & 0.08 & 3.21 & - & 3.4 \\
\hline
\end{tabular}




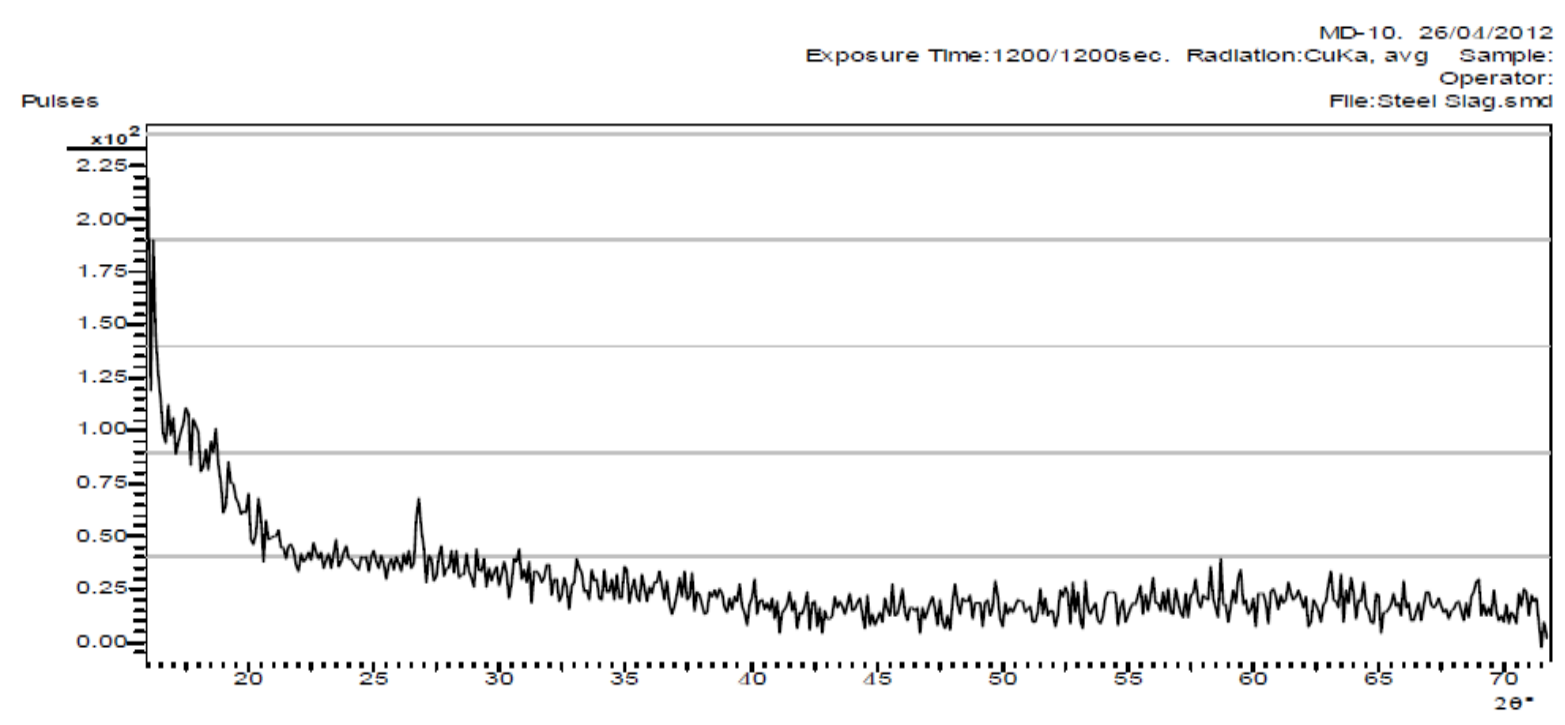

Figure 3: XRD spectrum of the steel slag

\subsection{Aggregate characterization}

The physical properties of sand, steel slag and granite were evaluated and the results are summarized in Table 2. Tests results show that the relative densities were 2480,2530 and $2710 \mathrm{~kg} / \mathrm{m}^{3}$ respectively but their bulk densities were 1530,1620 and $1680 \mathrm{~kg} / \mathrm{m}^{3}$ showing that they were of normal weight aggregates since their bulk densities were within the range of 1200 to $1750 \mathrm{~kg} / \mathrm{m}^{3}$ as recommended by ASTM C136. The results suggest that water absorption capacity of the steel slag (19.13\%) was about $87 \%$ of that of the sand (22.05\%) but there was appreciable difference in their moisture contents. The implication of this was that more water would likely be required to produce normal concrete than when equal amount of steel slag is used, because of the relative higher water absorption capacity of sand. Thus, reduction in water demand would likely save cost, which could have been expended in procuring mixing water.

Table 2: Physical properties and grading coefficients of aggregates

\begin{tabular}{lccc}
\hline \multirow{2}{*}{ Properties } & \multicolumn{3}{c}{ Aggregates } \\
\cline { 2 - 4 } & Sand & Steel Slag & Granite \\
\hline Specific Gravity & 2.48 & 2.63 & 2.71 \\
Bulk Density, kg/m ${ }^{3}$ & 1530 & 1620 & 1680 \\
Fineness Modulus & 2.59 & 3.55 & 7.24 \\
Water Absorption Capacity, \% & 22.05 & 19.13 & 14.20 \\
Moisture Content, \% & 38.30 & 37.41 & 19.23 \\
Coefficient of Curvature, $C_{c}$ & 1.0 & 1.0 & 1.2 \\
Coefficient of Uniformity, $C_{u}$ & 2.5 & 2.9 & 1.9 \\
\hline
\end{tabular}

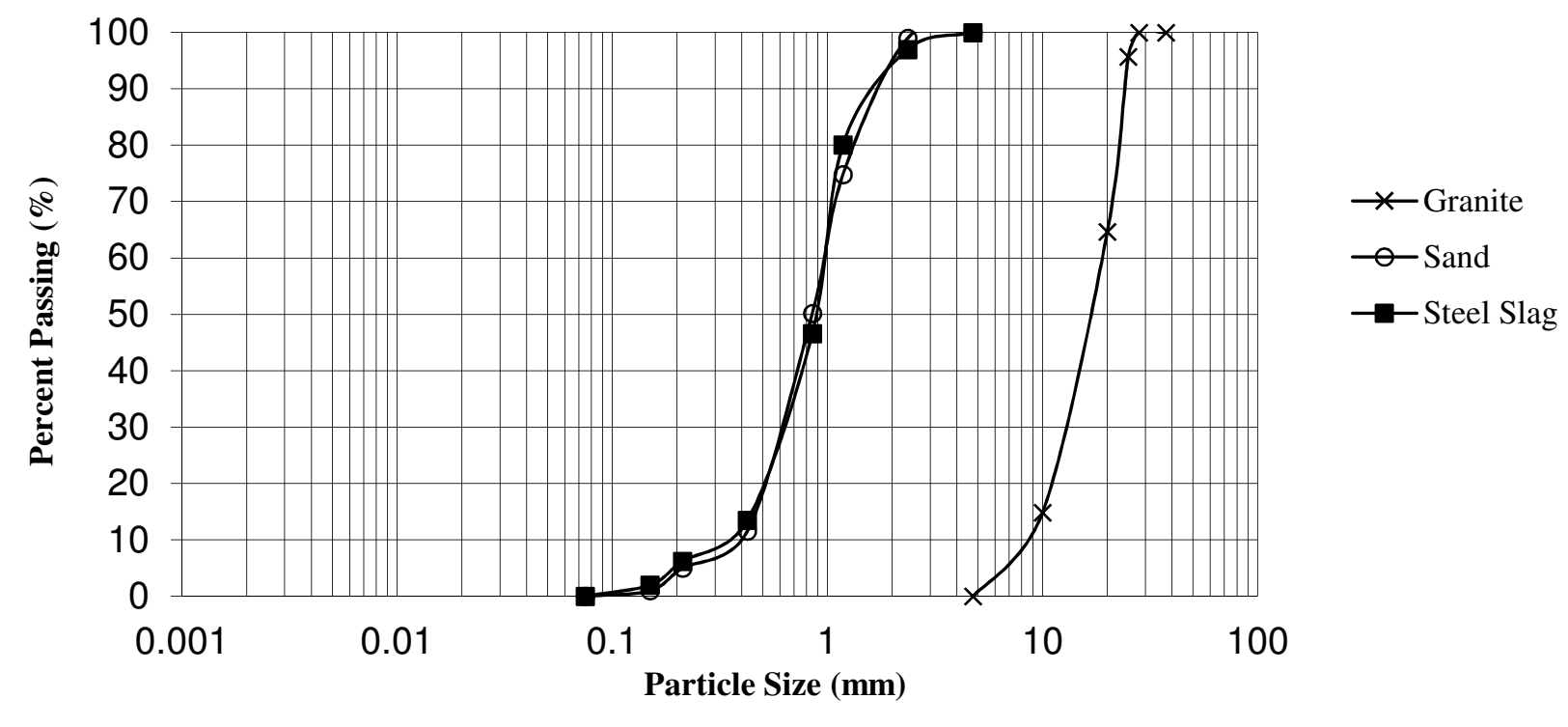

Figure 4: Particle-Size Distribution Curves of Aggregates 
For the gradation characteristics of the aggregates, the results of sieve analysis were plotted as particle-size distribution curves (Figure 4). It is observed that more than $90 \%$ of sand and SS passed the sieve No. 4 (4.75 $\mathrm{mm}$ ) while less than $5 \%$ were retained on sieve No. 200 . This observation indicates that both sand and SS could be categorized as fine aggregate appropriate for concreting.

The coefficients of curvature $\left(C_{c}\right)$ of sand and slag were 1.2 and 1.4 respectively, while their corresponding coefficients of uniformity $\left(C_{u}\right)$ were 2.5 and 2.9 (Table 2 ). The results indicate that both the sand and slag were clean because there were no finer particles (such as silts and clay) and were well sorted according to Unified Soil Classification System (USCS) detailed in ASTM D- 2487. Importantly, the gradation characteristics of the steel slag were not appreciably different from that of the sand. This similarity suggested that the variations in properties of normal concrete and concrete containing SS as replacement for sand were not likely due to gradation properties.

As for the coarse aggregate (granite), the $C_{c}$ and $C_{u}$ were within the specified range for well sorted coarse aggregates for concrete production (ASTM - 2487)

\subsection{Effect of Steel Slag on Density and Workability of Concrete}

In order to maintain standard consistency for all the concrete mixes, the slump value was kept within the range of $60 \pm 10 \mathrm{~mm}$ and the water-cement ratio $(\mathrm{w} / \mathrm{c})$ to achieve this was determined for each of the concrete mixes. The results of the $\mathrm{w} / \mathrm{c}$ ratio and densities of the hardened concrete cubes containing various proportions of steel slag are presented in Table 3. It is noticed that the water-cement ratio decreased with increase in the content of steel slag. A water-cement ratio of 0.62 was obtained to produce normal concrete ( $0 \%$ SS) of slump value of $60 \pm 10 \mathrm{~mm}$ while $0.57,0.53$ and 0.52 were obtained for concrete containing 25,50 and $75 \%$ steel slag for equal slump $(60 \pm 10 \mathrm{~mm})$.

Nevertheless, pure steel slag concrete $(100 \%)$ required $\mathrm{w} / \mathrm{c}$ of 0.50 to produce concrete of the same

Table 3: Water-cement ratios at constant slump and density of steel slag concrete

\begin{tabular}{ccccccc}
\hline Steel Slag & Water-Cement Ratio at & \multicolumn{4}{c}{ Density $\left(\mathrm{kg} / \mathrm{m}^{3}\right)$} \\
\cline { 4 - 6 } Content & Slump Range of $60 \pm 10$ & \multicolumn{4}{c}{ Curing Ages (Days) } \\
\cline { 4 - 6 }$(\%)$ & $\mathrm{mm}$ & 7 & 14 & 28 & 56 \\
\cline { 4 - 7 } & 0.62 & 2385 & 2388 & 2378 & 2389 \\
25 & 0.57 & 2391 & 2396 & 2395 & 2397 \\
50 & 0.53 & 2398 & 2401 & 2398 & 2404 \\
75 & 0.52 & 2411 & 2408 & 2412 & 2413 \\
100 & 0.50 & 2420 & 2424 & 2422 & 2423 \\
\hline
\end{tabular}

workability. Variations in the w/c could be attributed to different water absorption capacities of sand and slag (Table 2), in which sand has higher water absorption capacity than steel slag. Since w/c is a major factor that influences most engineering properties of concrete, it is expected that the inclusion of steel slag would have effect on the concrete produced from it.

Observation of the densities of the steel slag concrete in Table 5 revealed that the more the steel slag in the concrete the higher the density of the hardened concrete. For instance, the density obtained for normal concrete, at 28-day curing, was $2378 \mathrm{~kg} / \mathrm{m}^{3}$ while that of $100 \%$ steel slag concrete was $2422 \mathrm{~kg} / \mathrm{m}^{3}$, representing about $1.5 \%$ increase. The increase in densities observed in concrete containing steel slag could be due to higher bulk density and specific gravity of steel slag over the replaced sand (Table 2).

The results further showed that the age of curing did not have appreciable effect on all the concrete mixes. However, both the normal and steel slag concretes could be categorized as normal dense concretes, since their densities were within the range of normal weight concrete.

\subsection{Effect of Steel Slag on Compressive and Flexural Strength}

The results of the compressive and flexural strength obtained for the concrete mixes containing different proportions of steel slag fine aggregates are presented in Table 4. It is observed that the compressive strength of all the mixes increased with age. The results also showed that the compressive strengths of the steel slag concretes were higher than that of natural aggregate concrete. The trend was that the compressive strength increased with up to $50 \%$ replacement of sand with slag content for all the ages, but dropped afterwards at 75 and $100 \%$ replacement levels for all the ages other than early age of 7 days when the strength of slag concrete was higher than normal concrete irrespective of the content of slag as shown in Figure 5. 
Table 4: Compressive and Flexural Strength of Steel Slag Fine Aggregate Concrete

\begin{tabular}{ccccccccc}
\hline & \multicolumn{3}{c}{ Compressive Strength (N/mm ${ }^{2}$ ) } & \multicolumn{4}{c}{ Flexural Strength (N/mm $\left.{ }^{2}\right)$} \\
\cline { 2 - 9 } Steel Slag Content (\%) & \multicolumn{3}{c}{ Curing Ages (Days) } & \multicolumn{4}{c}{ Curing Ages (Days) } \\
\cline { 2 - 9 } & 7 & 14 & 28 & 56 & 7 & 14 & 28 & 56 \\
\hline 0 & 9.85 & 14.70 & 21.48 & 21.61 & 2.27 & 2.54 & 2.74 & 3.03 \\
25 & 10.42 & 15.56 & 23.59 & 24.14 & 2.24 & 2.52 & 2.72 & 3.16 \\
50 & 10.67 & 15.93 & 23.95 & 24.28 & 2.25 & 2.45 & 2.42 & 3.23 \\
75 & 10.76 & 14.14 & 21.16 & 21.59 & 2.21 & 2.34 & 2.38 & 3.23 \\
100 & 10.96 & 14.37 & 21.06 & 21.46 & 2.25 & 2.37 & 2.34 & 3.30 \\
\hline
\end{tabular}

Quantitatively, at age 7, the strength of normal concrete was $9.85 \mathrm{~N} / \mathrm{mm}^{2}$ while that of $25,50,75$ and $100 \%$ slag aggregate concrete were $10.42,10.67,10.76$ and 10.97 $\mathrm{N} / \mathrm{mm}^{2}$ respectively. The reason for this behaviour could be that the interlocking between the cement paste and steel slag was stronger than with sand. It could also be due to high content of iron oxide in the slag, which contributes to early strength development. Conversely, different and consistent behaviour was noticed at later ages of 14, 28 and 56 days, which could be more dependable in assessing the strength characteristics of normal and steel slag aggregate concrete.

As observed from the results (Table 4), the 28-day strength of natural aggregate concrete ( $0 \%$ SS) was $91 \%$ of that of $25 \%$ SS, and $89.7 \%$ of $50 \%$ SS concrete; but was slightly higher than those of 75 and $100 \%$ slag concrete by 1.5 and $2 \%$ respectively. The same pattern was noticed for ages 14 and 56 days. This behaviour suggested that SS contributed to the strength development of concrete when not more than $50 \%$ of sand by weight is replaced with it. The reason for this performance could be attributed to its properties. It was observed that steel slag contained more of amorphous silica, which has potential to react with calcium hydroxide produced during cement hydration to produce more calcium silicate hydrate gel (C-S-H) for more strength. It appeared that up to $50 \%$ steel slag content could be appropriate as optimum beyond which the steel slag appeared dormant, which could have been responsible for relative low strength when 75 and $100 \%$ slag were used (Table 4 ).

This study did not investigate the alkali-silica reaction of the steel slag. Thus, it would be necessary to investigate accelerated and long-term alkali-silica reaction of steel slag fine aggregate to be able to ascertain this assertion. It is interesting to note that the 28-day compressive strength of the normal and steel slag aggregate concretes were all higher than 17 $\mathrm{N} / \mathrm{mm}^{2}$ recommended by [20] for structural concrete. This limit is indicated by a line as shown in Figure 5 .

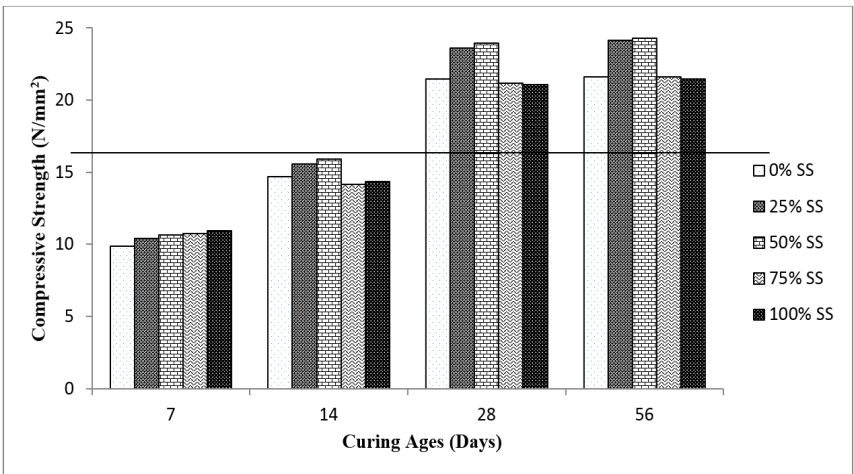

Figure 5: Compressive Strength of Steel Slag Aggregate Concrete at different Curing Ages

The flexural strength of normal concrete and SS concrete increased with age as compressive strength did. Except at 56 days when the flexural strength increased with increase in SS proportion, at other ages (before 28 days) there appeared to be no distinct pattern. The reason for this behaviour could not be precisely identified. Nevertheless, the flexural strength of concretes containing SS were not appreciably different from those of normal concrete for all proportions of SS. This result suggested that steel slag may not have negative appreciable impact on the flexural strength of concrete. Of interest is the ratios of flexural to corresponding compressive strength for each concrete mix were found to be within the range of $0.08-0.11$ [21]. The import of this performance was that the flexural strengths obtained were still acceptable. Generally, the flexural strength of concrete is improved by inclusion of reinforcing steel bars.

\section{CONCLUSION}

This study investigated the use of steel slag as partial replacement of sand in concrete production. The properties of the steel slag were equally examined. The study concluded as follows:

1. The results of XRF and XRD tests suggested that the steel slag contained high silica and ferric oxides content which was amorphous with traces of crystalline particles. 
2. Physical properties of the steel slag indicated that it can be used as replacement for river sand in concrete production. Steel slag had low water absorption than sand and thus reduce amount of water required for concrete containing SS.

3. The 28-day compressive strength of concrete containing 25 and $50 \%$ slag were $9.8 \%$ $\left(23.59 \mathrm{~N} / \mathrm{mm}^{2}\right)$ and $11.5 \%\left(23.95 \mathrm{~N} / \mathrm{mm}^{2}\right)$ higher than that of the normal concrete $\left(21.48 \mathrm{~N} / \mathrm{mm}^{2}\right)$, which showed that steel slag has appreciable influence on the compressive strength of concrete when up to $50 \%$ of sand was replaced with slag.

4. Steel slag did not have negative impact on the flexural strength of concrete. Thus, SS could be suitable substitute for sand, as fine aggregates in concrete production.

\section{REFERENCES}

[1] ACI Committee E-701. "Aggregates for concrete ACI: Materials for Concrete", Construction Education Bulletin E1-99:1-26. 1999.

[2] Kamran M. N. “CM 425-Concrete technology”, University of Washington, Winter Quarter. http://courses.washington.edu/cm425/aggregate.p df. Accessed: June 24, 2013.

[3] Winfield, M. and Taylor, A. "Re-balancing the Load: the need for an aggregates conservation strategy for Ontario", The Pembina Institute, 2005, pp. 8-9.

[4] Kulkarni, G. J., Dwivedi, A. K., Jahgirdar, S. S. “Textile mill sludge as fine aggregate in concrete, Global Journal of Researches in Engineering, Vol.12, Issue 2, Version 1, 2012, pp.20 - 26.

[5] Pofale, A. D. and Deo, S. V., 2010,Comparative long term study of concrete mix design procedure for fine aggregate replacement with fly ash by minimum voids method and maximum density method, $K S C E$ Journal of Civil Engineering, Vol. 14, No. 5, 2010, pp.759-764.

[6] Jones, M. R. and McCarthy, A. "Utilizing unprocessed low lime coal fly ash in foamed concrete", Fuel, Vol. 84, Issue 11, 2005, pp.1398-1409.

[7] Rebeiz, K. S., Serhal, S. P., and Craft, A. P. "Properties of polymer concrete using fly ash", Journal of Materials Engineering, Vol. 16, Issue1, 2004, pp.15-19.

[8] Alnuaimi, A. S. "Effects of copper slag as a replacement for fine aggregate on the behavior and ultimate strength of reinforced concrete slender columns", TJER, Vol. 9, No. 2, 2012, pp.90-102.

[9] Taha R. A, Alnuaimi, A. S, Al-Jabri KS, Al-Harthy, A. S. "Evaluation of controlled low strength material containing industrial by-product", Building and Environment, Vol. 42, 2007, pp.3366-3372.
[10] Shoya M., Sugita S., Tsukinaga Y., Aba, M., Tokubasi K. "Properties of self-compacting concrete with slag fine aggregates", International conference on exploiting wastes in concrete. University of Dundee, 1999, pp.121-130.

[11] Shahul Hameed, M. and Sekar, A. S. S. "Properties of green concrete containing quarry rock dust and marble sludge powder as fine aggregate, $A R P N$ Journal of Engineering and Applied Sciences, Vol.. 4, No. 4, 2009, pp.83-89.

[12] Dhir, R.K., McCarthy, M.J. and Tittle, P.A.J. "Use of conditioned PFA as a fine aggregate component in concrete", Materials and Structures, Vol. 33, 2000, pp. $38-42$.

[13] Hasbi Y., Huseyin, Y. A., Ilhami D., Osman, S and Gokhan, D."Effects of the fine recycled concrete aggregates on the concrete properties Sciences", International Journal of the Physical, Vol. 6, No. 10, 2011, pp.2455-2461.

[14] Akinwumi, I., Adeyeri, J., and Ejohwomu, 0., 2012,"Effects of steel slag addition on the plasticity, strength, and permeability of lateritic soil", ICSDEC 2012, pp.457-464.

[15] Mohammed, N., and Pofale, A. D. "Experimental investigation of using slag as an alternative to normal aggregates (coarse and fine) in concrete", International Journal of Civil and Structural Engineering, Vol. 3, No 1, 2012, pp.117 127.

[16] Han Ay Lie. "Steel-slag as substitute to natural aggregates, properties and the interfacial transition zone", TEKNIK, Vol. 30 No. 1, 2009, pp.1-7.

[17] Mohd Rosli H., Nur, I. Y., Mohd Fahmi, M. S., Mohd Azizi, A., Mohd Anwar, S., and Wasid F. R."Steel slag as an aggregate replacement in Malaysian hotmix asphalt", International Scholarly Research Network (ISRN) Civil Engineering, Vol. 2012, pp.1-5.

[18] Salau, M. A., Ikponmwosa, E.E. and Ogunbajo, A. B."Investigation of the use of steel slag (Tap Slag) as aggregate in concrete", Proceedings of International Conference on Advances in Cement and Concrete Technology in Africa, Johannesburg, 2013, pp.543 550.

[19] Lewis, D. W., 1982, "Properties and uses of iron and steel slags", A lecture presented at Symposium on Slag National Institute for Transport and Road Research South Africa, February, 1982.

[20] CIP 35 - Testing Compressive Strength of Concrete, Technical Information, National Ready Mixed Concrete Association (NRMCA), Silver Spring, MD 20910. pp. 1-2.

[21] Shetty, M.S., 2006, Concrete technology-theory and practice, S. Ch \& Company Ltd., Multicolor edition. 